\title{
THE DECLINING BIRTH RATE IN SWEDEN*
}

\author{
BY \\ ARVID WALLGREN \\ Sweden \\ (Received for Publication June 15, 1950)
}

The birth rate varies considerably in different countries. Shortly before the war the lowest birth rate was reported from Austria and the highest from Mexico, and probably about the same relationship exists today (Fig. 1). If the birth rate is
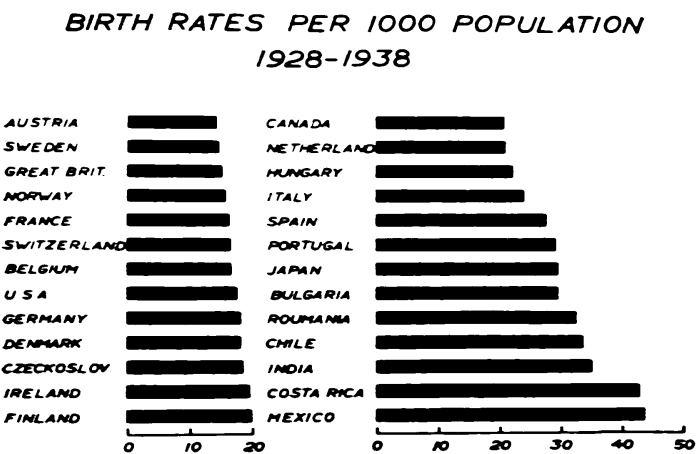

FIG. 1 .

constantly very low there will eventually be a decrease in the population; if it is very high an increase will follow, other factors remaining unchanged. The threshold value of the birth rate constituting the border line between decline and increase of a population is 20 , that is 20 newborns annually for every 1,000 inhabitants. As is shown in Fig. 1 there are several west and north European countries, Great Britain and Sweden among them, that have $\mathrm{a}$ birth rate below 20 , and in the long run these countries are threatened by depopulation. These two countries face the common problems and consequences of a declining birth rate; the conditions in Sweden, however, are worse than in Britain as the birth rate in Sweden has fallen lower. In this lecture I will consider some of the more important problems of a too low birth rate as they have already shown themselves in Sweden. The same problems should be of interest in Great Britain. I will draw attention to

* The second Windermere Lecture delivered to the British Paediatric Association at Windermere in April, 1950 some social consequences, and I will discuss the declining birth rate from the medical, and especially the paediatric, point of view.

In Sweden we have population statistics dating back to 1750 . As will be seen from Fig. 2 the birth rate has not been below 20 for any considerable length of time. At the end of the last century and at the beginning of the present the birth rate was rather high, 25 or more, although a tendency to decline was apparent. We had a sufficient number of newborns until the end of world war I. But from 1919 onwards the birth rate has been below 20, reaching its lowest level, $13 \cdot 6$, in 1934 . Then a rise began, and 10 years later the rate was again 20 for some years. The last available figure, for 1949 , is 17 . I will return later to the cause of this temporary rise in the birth rate.

It is of interest to study how the declining birth rate has influenced the population. So far there has been a steady increase but in a decade or two the number of inhabitants will be fewer, if they are not artificially kept at the present level by immigration.

Before the present critical situation the question

$$
\begin{gathered}
\text { POPULATION IN SWEDEN } \\
\text { I75O-I95O }
\end{gathered}
$$

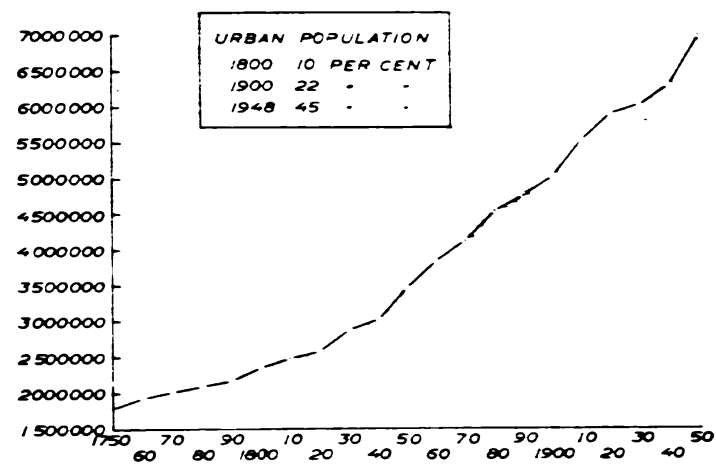

FKG. 2. 
was often asked, 'Is some decrease of a population to be regarded as a disadvantage? Was there not in some areas already, under normal conditions, a certain surplus of industrial workers with consequent unemployment ?' This unemployment and the difficulty of getting a sufficient livelihood resulted, about 50 to 100 years ago, in an emigration from Sweden, especially to the United States (Fig 3).

EMIGRANTS

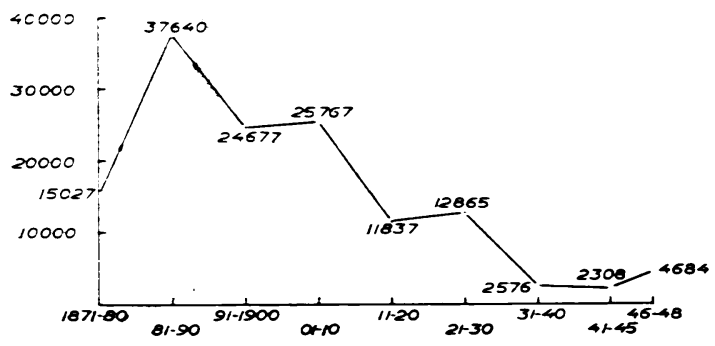

FIG. 3.

This was greatest at the end of the last and the beginning of this century. At that time, before the rapid development of industrialization, Sweden had no doubt too many inhabitants. It has been maintained that if all these young, efficient emigrants had remained in their home country we should now have about ten million instead of seven million inhabitants. This would probably be too many and would have given rise to social and medical problems of different kinds. That a surplus of inhabitants may constitute a great disadvantage is apparent now in several south and east European and far eastern countries. But why is it important that the number of inhabitants should remain constant or at all events not be reduced? I cannot quote all the arguments that have been advocated and want only to stress some consequences of social and medical importance which can with certainty be foreseen.

\section{The Swedish Population Pyramid}

In a normal population there is a great number of children and adolescents, a small number of old people, and in between a large number of individuals of productive age. If each age group of the population is placed on the next younger one a figure results shaped like a triangle or a pyramid, the so-called population pyramid (Fig. 4). From the form of the population pyramid the composition of the population in the near future can be deduced. It can be calculated in advance how much every age group will be decreased by death. A low birth rate will, after some decades, cause a relative
Swedish Population in 20 year groups

EACH FIGURE $=100,000$ PERSONS

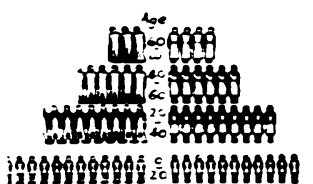

1920

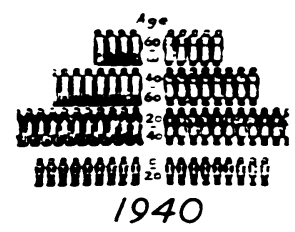

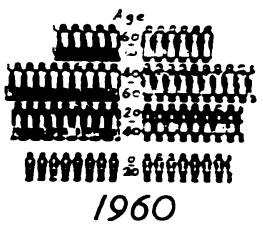

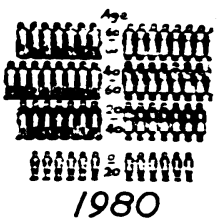

1980
FIG. 4.

decrease in the productive age groups and an increase in the number of the unproductive 'old age ' group. Only naturally occurring catastrophes, widespread epidemics, or war may cause any marked deviation from such a development.

The form of the Swedish population pyramid has changed, influenced by the declining birth rate, and we can now conclude what may happen in the future. The number of individuals in the youngest productive age group, 20-35 years, is going to be markedly reduced, from $1,600,000$ in 1940 to $1,200,000$ in 1960 , while the old unproductive group will be enlarged (Fig. 5). To-day we have 600,000

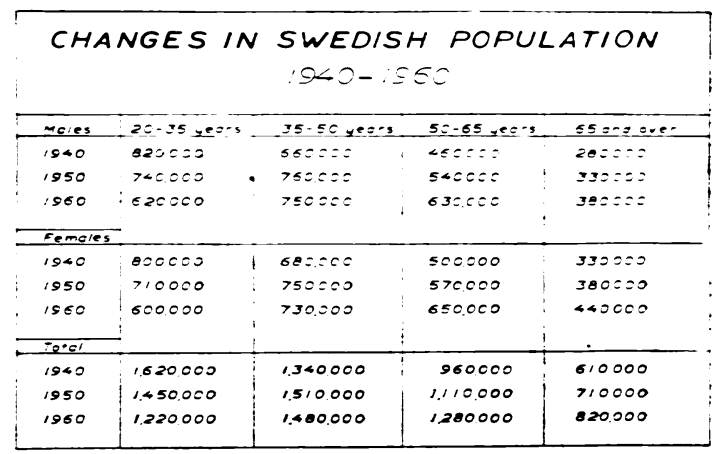

FK. 5.

old people; in 20 years' time they will have increased to 820,000 . In 1985 we will have double the number of old people compared with to-day. The decreased death rate has contributed to this increase of old people. The expectancy of life (Fig. 6) in Sweden has been gradually increasing and is at present about 70 . 


\section{LIFE EXPECTANCY $1816-1945$}

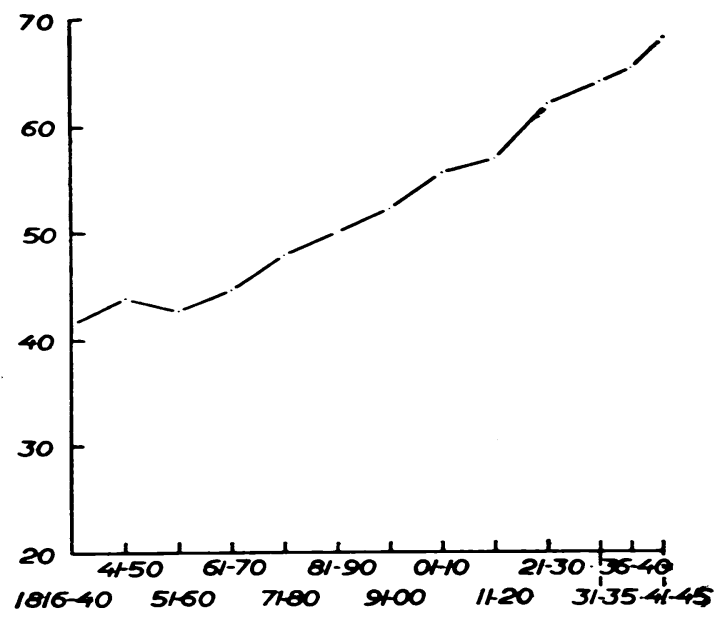

Fig. 6.

It is this combination of a small number of births and the increasing number of old people that constitutes the seriousness of the present situation. It is the productive individuals who have to give birth to children and to take care of them and of old people and this task will become more and more difficult; while the number of people belonging to this productive group is decreasing, the unproductive groups are increasing. In 1880, nine people were responsible for only one old person; in 1980, nine people will have to support three old men or women. A problem of the future will doubtlessly be the building of homes and hospitals for old people, and this task will be made more difficult by a shortage of nurses. The problem of taking care of old people has already become more and more obvious and pressing in Sweden. There have been many alarming articles on this question in newspapers and journals, and many lectures and discussions at medical and social welfare meetings. Geriatry will without doubt be a very important branch of internal medicine.

A factor which makes the situation especially serious is that Swedish women of childbearing age are rapidly decreasing in number. This development is exactly the opposite to that of the old age group. To-day we have 800,000 females of $20-45$. Every year their number is decreasing by many thousands. In 20 years' time the number will be reduced to only 600,000 . The fewer the females of childbearing age the more difficult will it be to obtain the necessary birth rate of 20 per thousand corresponding to about 130,000 children annually.

\section{The Marriage Situation}

I have pointed out that the birth rate has, as a matter of fact, increased lately from 13.6 in 1934 to 21 in 1945 (Fig. 7). This development caused general satisfaction and hope. It was also suggested that everything was all right again. This was unfortunately a somewhat premature conclusion as the birth rate is again falling. The temporary increase in the number of births is principally due

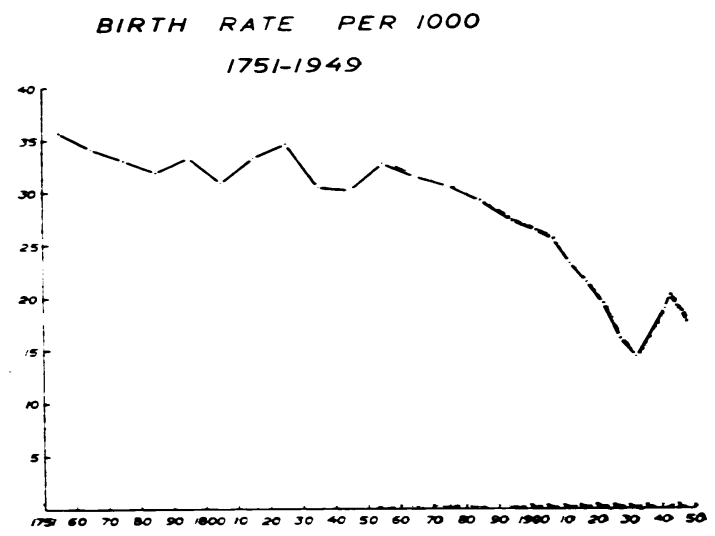

Fig. 7.

to the very high marriage rate during recent years (Fig. 8). It is evident that the largest number of infants are born in the youngest families, while the lowest number is born in older families. In the former there are three times as many children born annually as in marriages five to ten years old. The variations in the marriage rate are seen in the table. In 1942-45 there were 62-63,000 marriages annually. Unfortunately it is not possible to depend on the same rate in the future. As soon as the small age groups from 1930 onwards become old enough for marrying there will be a decrease in the absolute

MARRIAGES

1800-1949

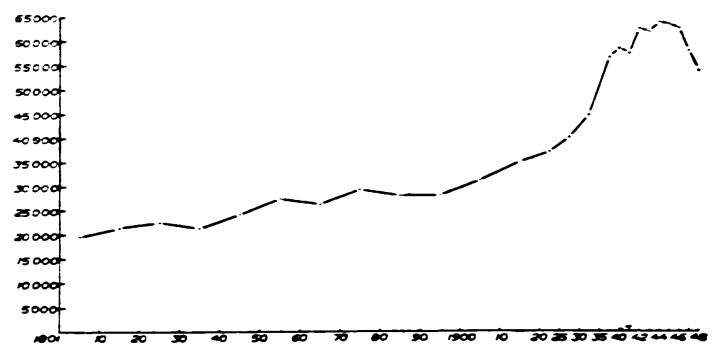

Fig. 8. 
number of marriages. In 1934 only 85,000 infants were born. Even if all these children should develop normally and reach maturity we could only expect at most 42,000 marriages, that is, one-third fewer than in the middle of the last decade. In addition an artificial, abnormal geographical distribution of men and women throughout the country will make marrying still more difficult. Nature has tried to guarantee that every man should get a wife, and every woman a husband. At birth there are always more boys than girls, about 106 boys to 100 girls. By a higher death rate among the males this relationship is changed during childhood, and when men and women have attained sexual maturity their number is identical and theoretically speaking all could marry. There are two factors that can interfere with this favourable marriage situation: wars and changes in the male-female composition of the population in different areas. We have not been involved in any war for the last 140 years. However, the influence of the other factor is evident. There has been a continuous influx from rural to urban districts, the adolescent girls moving into the towns in a greater number than the adolescent boys. Consequently there is a deficiency of women in the country and a surplus in the cities. In 1940 there were 700 unmarried adult women in the country for every 1,000 adult men. Out of 100 young farmers, aged $20-35$, there are 40 who would , have difficulty in finding a wife; the girls they should have married had departed to a town. This relationship is reversed in the towns where thousands of unmarried women face the problem of finding a husband. In the city of Stockholm there are about 1,500 women for every 1,000 men; and in 1949, there were 60,000 more females than males. This can only lead to a lower marriage rate and therefore to a decreased legitimate birth rate. As long as female workers are as ardently required in towns as they are now, and as long as they are much better paid than in the country, then we shall have a migration of young females to the towns. They consider urban life more tempting, exciting, and interesting than rural.

For many married women in the cities working outside their homes, it is often very difficult to manage the household without a servant. If they get no maid, then they cannot have children, and if they get a girl from the country as a maid, the latter is prevented from getting married because she has left behind the man who may have been her husband. For the continuation of the population at the present level, it is important that rural adolescent girls do not move to urban areas but remain in their home district and marry one of their neighbours.
The Swedish Law of Abortion

This abnormal migration to the cities has also other consequences which are of importance from the point of view of preserving the population. The young girl who moves in to the town cannot be married because she cannot find any man to marry. But it is, on the other hand, too easy for her to develop friendships which result in pregnancy. The unmarried expectant mother knows fairly well the attitude of society to her difficult position, and in despair believes that the only solution to her problem is to get rid of the expected child. She thinks that she has the right to determine the fate of the germinating life in her body and she turns to a quack abortionist. How many such criminal abortions there are annually in Sweden nobody can tell because most of them never come to our knowledge. Their number is considered to be about 10,000 . In Stockholm the annual number of cases is probably about 1,000 . Every criminal abortion is a lost life which ought to have been spared to our country with its too few children, and it is obviously not only of an ethical but of a national interest to combat criminal abortion. In order to diminish the number of criminal abortions a law was passed by the Swedish parliament 10 years ago allowing legal termination of pregnancy under certain conditions, e.g. mental disturbances connected with pregnancy. Very few women took advantage of this law during the first five years. Then social workers were appointed for the specific purpose of contacting potential abortion cases to try to determine the motives of these women, to give them advice and help, and the necessary moral and economic support, in order to prevent criminal abortion. In this they often succeed; instead there has occurred a marked and continuous increase of legal abortions. In 1949 the social workers in Stockholm were consulted by 2,000 pregnant women who wanted abortion. In 1,000 cases legal abortion was granted and performed; in about 800 cases the expectant mother was persuaded to give birth to her child. In the whole of Sweden there were more than 5,000 legal abortions last year. This corresponds to one legal abortion for every 300 women in the childbearing age annually or to one legal abortion for every 20 deliveries. Their number is now approaching the estimated number of criminal abortions which the law allowing legal abortion should abolish. Responsible people have become alarmed by the consequences of the law, and some doubt as to the justice of the indications has been aroused. In addition people have been worried by serious complications of the operation. Some months ago the government appointed an expert committee to study the problem and to suggest 
changes and improvements in the law. I have been told that a similar law has been discussed in Great Britain but so far has not been pressed as public opinion is against it. From the point of view of the population problem in our country with its low birth rate, the value of legal abortions as a weapon against criminal abortions is doubtful, also when one considers the decrease in fertility so often próduced.

Children born out of wedlock are, as a rule, not only from the point of view of the mother but also of the community, ' unwanted children.' They make bad citizens more frequently than other children and are more often in trouble with the police and the community. In Sweden as a whole every sixth child is illegitimate; of those admitted to reformatory schools for delinquent juveniles every third child belongs to this category. The cause of the increased incidence of delinquency among illegitimate children is probably not, in the majority of cases, due to unsatisfactory hereditary qualities, but rather to their inferior upbringing. They are often boarded out in foster homes that are frequently changed, and the children have no feeling of security. If the unmarried mother tries to take care of her child herself, she usually places him in a day nursery with its lack of individual care and education.

\section{The Problem of the Racially Unfit}

In the choice between no children at all and good children born of unmarried mothers, the community prefers the last. An infant born out of wedlock can sometimes be a more valuable member of the community than a child born of a married mother, if the former is of good quality, and the latter is not. We want children who are healthy, who can develop in a normal way and have satisfactory hereditary qualities. Those who are degenerated, or become imbecile, psychotic or antisocial, whether illegitimate or legitimate, should never have been born. No matter how important it is to increase the birth rate, we must never forget that quality is preferable to quantity. Every measure aiming at an increase in the population should promote the fertility among responsible people and prevent the fertility of inferior persons. Otherwise the breed may degenerate. Birth control is, therefore, an important factor in sound population planning. Unfortunately voluntary birth control is generally applied in families with satisfactory genetic backgrounds, with good social conditions and a solid economy, while it is scarcely applied at all in families where procreation is less desirable. At least, one gets that impression when observing the great number of children in families who are hereditarily unstable and, from the point of view of race, unsatisfactory. People belonging to the latter category multiply many times more rapidly than do other people. In the Swedish population we are burdened with an antisocial, criminal group of foreign extraction, the so-called tattare; they have, on an average, four times as many children as ordinary Swedish families.

Over 200 years ago the Swedish government recognized the danger of deterioration of the race by the birth of hereditarily unsatisfactory children, and tried to prevent the consequences by a law prohibiting such marriages. This concerned imbeciles, lunatics, and a certain group of epileptics. This prohibition still remains, and it may be justified from a medical point of view based on sound grounds, but in practice it is illusory; if the children are not allowed to be born if the couple are married, then they are born without any marriage, and often in greater number than in healthy families. The only real, rational, and medically to be recommended method of preventing births of unwanted children in degenerate families is sterilization or lasting internment. As the latter method is inhuman and impossible to carry out for financial reasons, sterilization is the only way. It is, of course, not possible to determine in advance the remote effect of sterilization of degenerate individuals on the incidence of inherited genetic factors in the population. One thing is, however, evident; as parents such people are unfit. The rearing of their children must sooner or later be handed over to the community, and this is very expensive with the system now in force in Sweden. The building of children's homes, of hospitals for mental defectives, of reformatory schools for delinquent juveniles, constitutes a very heavy financial burden on the community, not to mention the annual working expenses. The annual cost for one child in such an institution is about the same as the average income for a labourer with a wife and a family of three or more children. These economic factors are strong arguments in favour of the sterilization of mentally defective and degenerate individuals.

Sweden has been rather slow in tackling these problems. Our first law on sterilization was passed in 1935, and a somewhat improved law a few years later, but it is still not sufficiently effective. It is, for example, still not permitted to sterilize a person, responsible in the legal sense, without his or her consent, a procedure which is often highly desirable. Such is the case with the antisocial group of the Swedish population just mentioned, the so-called tattare. They have to decide for themselves whether they want to be sterilized or not, and nobody, of course, accepts the suggested operation. It must 
be regarded as a highly misdirected humanity on the part of the community to support and take care of numerous degenerated, child-producing individuals without at the same time sterilizing them. In this way the country burdens its loyal citizens and prevents them by heavy taxation from giving birth to their own children. We get 'elf children ' instead of those we cannot afford and who should have been but were not born.

\section{The Infant Mortality Rate in Sweden}

For the maintenance of a population it is not sufficient that children are born healthy with a satisfactory genetic background; they must also be cared for and brought up in such a manner that they remain alive and in good health. In this respect, considerable improvements have occurred but much has yet to be done. In comparison with other countries the infant mortality rate in Sweden is very low (Figs. 9 and 10). According to the last

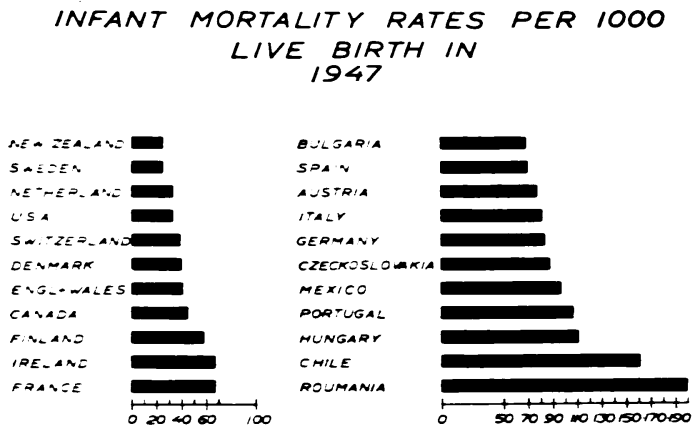

FIG. 9.

INFANT MORTALITY RATES IN CAPITALS IN 1948 PER 1000

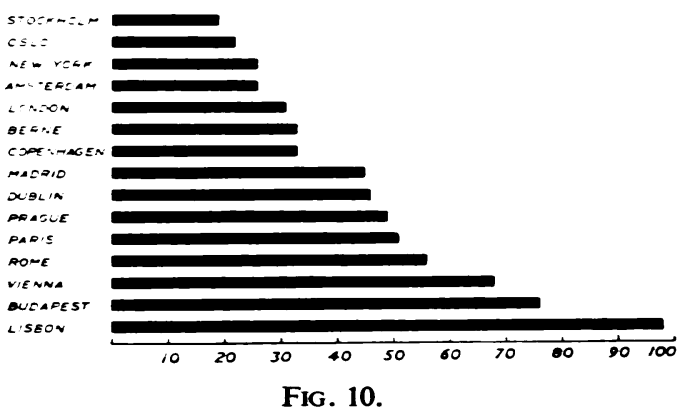

report it was only 27 per thousand. If we go as far back as our mortality statistics permit, to 1750 , we find that at that time, more than 200 out of every 1,000 newborn babies died during the first year of life. If we should have had the same infant $\frac{D}{\infty}$. mortality rate now, we should have annually about 20-25,000 young infants fewer. This excellent improvement in the mortality rate is due to the prevention of acquired diseases in children.

To what new low level our infant mortality rate may decrease is difficult to estimate. In the northern districts of Sweden it is high compared with the country as a whole, but especially high compared with some of the southern districts. If the mortality rate could be lowered in the northern part of Sweden to the same level as in the southern part the average mortality rate would decline considerably and our country be enriched by some thousands of children. In our large cities the mortality rate is much lower than that of the whole country; in Stockholm, for instance, it is only 19 per thousand. In the cities the child welfare services are better than in the rural districts; preventive measures have been more successful and the access to physicians, especially paediatricians, is easier. Before 1920 the position was reversed: a lower mortality in the country than in the towns. Since then it has fallen to a greater extent in urban areas so that in 1946 the rates were 24.5 per thousand in the cities and $28 \cdot 2$ per thousand in country districts.

\section{The Neonatal Mortality Rate in Sweden}

No matter how excellently the children are careg for after birth, they can develop fatal diseases before birth or before any prophylactic measures have had time to become effective. Even the best child welfare service cannot be fully effective in the early days of life. It is well known that the neonatal mortality in many countries, including Sweden, has not shown any tendency to decrease (Fig. 11). These problems
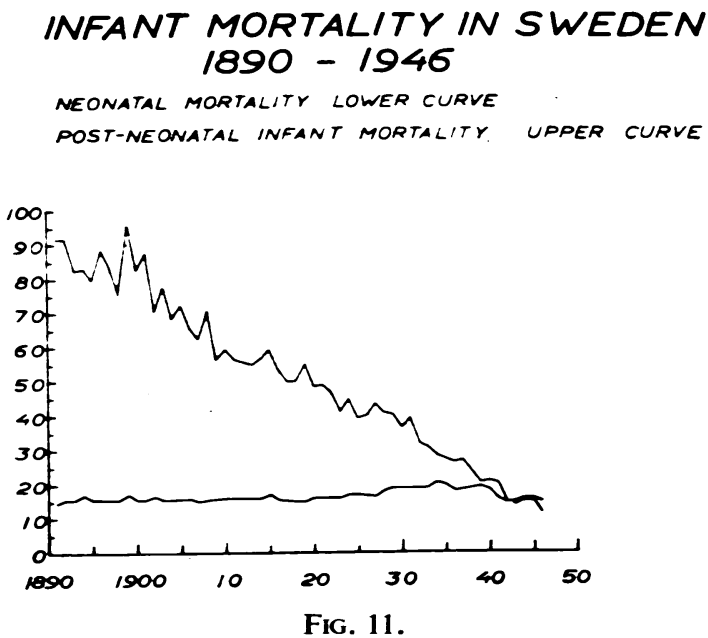

Fig. 11 
were well presented by Professor Moncrieff at the International Congress of Paediatrics in 1947. During the past 50 years it has remained at much the same level and, indeed, during the last 10 to 20 years, has shown a tendency to rise. This must be regarded as an unsatisfactory development. A closer study shows that this change for the worse concerns only the first five days of life. A similar trend has occurred with the stillbirth rate (Fig. 12).

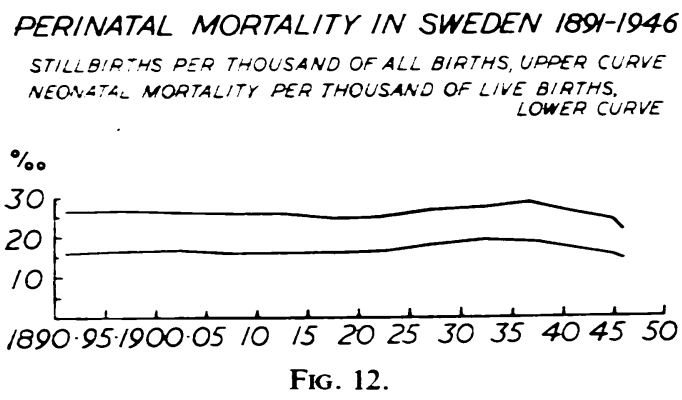

The curves in both cases run roughly horizontally and have the same tendency to rise. The similarity of these two curves, the stillbirth and the neonatal death rate, suggests that the causes of death in stillborn infants and in infants who die shortly after birth are much the same. Together, they include thousands of victims annually and in this way bring about a considerable decrease in the group of surviving children. If these two categories of death could be totally eliminated the increase in the number of Swedish children should be between 4,000 and 5,000 every year.

The social, hygienic, economic, and psychological factors, which have brought about a considerable decrease in mortality during the rest of the first year of life, have apparently had little influence on either the stillbirths or neonatal death rate (Fig. 13).

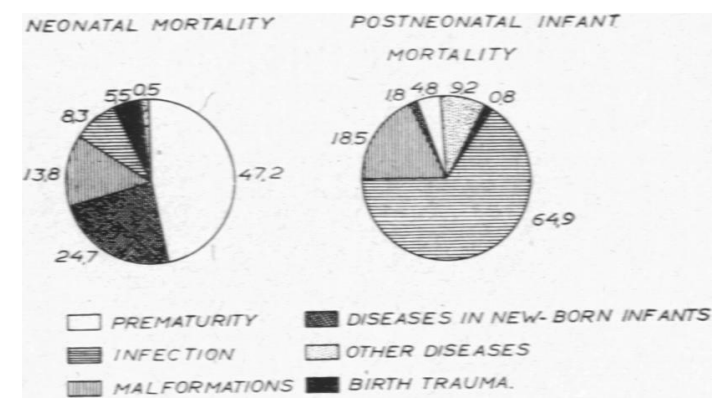

Fig. 13.

This is because neonatal mortality, with relatively few exceptions, results from illnesses, developing before or during delivery, while the mortality after the newborn period is principally due to diseases acquired after birth. These latter can, to a considerable extent, be prevented by a good infant welfare service and it is for this reason that this rate has decreased so much. The neonatal death rate can only to a very small degree be improved by preventive measures after birth.

The most important measure in the fight against the high neonatal mortality is obviously the prevention of prematurity and providing optimal care of the prematures. This means the satisfactory care and supervision of the pregnant woman to prevent, detect, and treat those diseases of pregnancy that can result in a premature delivery or a stillbirth; to guarantee to the mother suitable social conditions; to remove causes of anxiety, overwork, and privations of various kinds; and to advise against careless and imprudent living. This is the aim of the maternity welfare centre (Fig. 14). In these centres pregnant women are examined and their state of health and living conditions supervised by physicians and midwives; they are given information
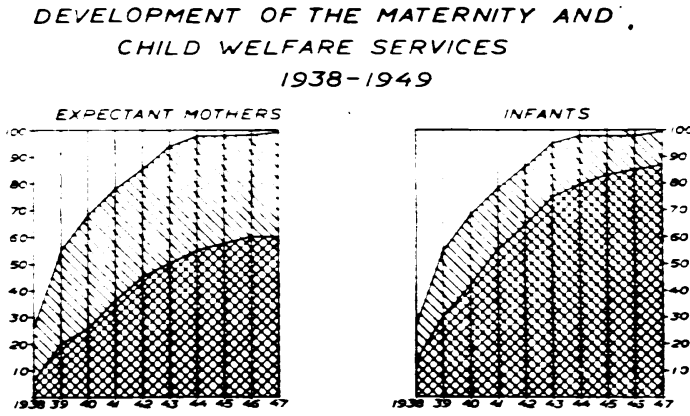

DUTTENDED WELFARE CENTRES

WO DID NOT ATTEND WELFARE CENTRES ALTHOUGH THEY WERE AVAILABLE

FIG. 14.

about diet, hygiene, and mode of living to ensure, as far as possible, a pregnancy and delivery free from complications. This branch of preventive medicine on a nation-wide basis was introduced in Sweden 15 years ago. It has since then developed slowly, and we hope that, when fully accomplished and adequately organized, it will play a more and more important part in the lowering of the neonatal mortality rate, and therefore, be of considerable value from the point of view of an increase in the population.

That a good maternity welfare service should improve the chances of life for newly born babies is shown by a comparison of the neonatal death rates of children born out of wedlock with those of married mothers (Fig. 15). The prospects of children born out of wedlock have been particularly 


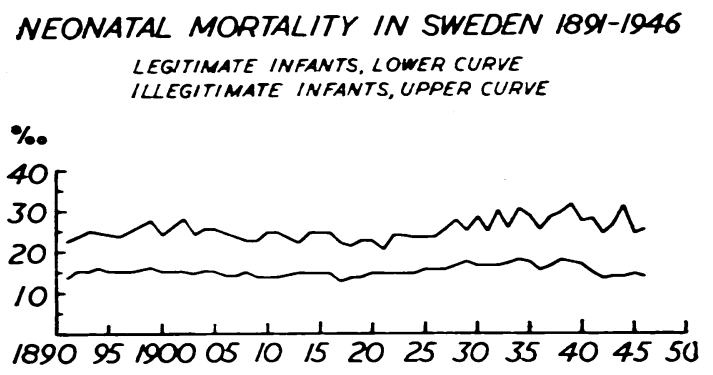

Fig. 15.

bad, due both to ignorance on the part of the mother and to unsatisfactory social conditions. The mother has to start work as soon as possible after delivery, and therefore, she is unable to look after the child herself, but must board it out. The child is, as a rule, sent to the least expensive foster home which is often, at the same time, the least satisfactory one. It is not surprising then that the mortality rate, especially some decades ago, was considerably higher among the illegitimate children than among the legitimate (Fig. 16).

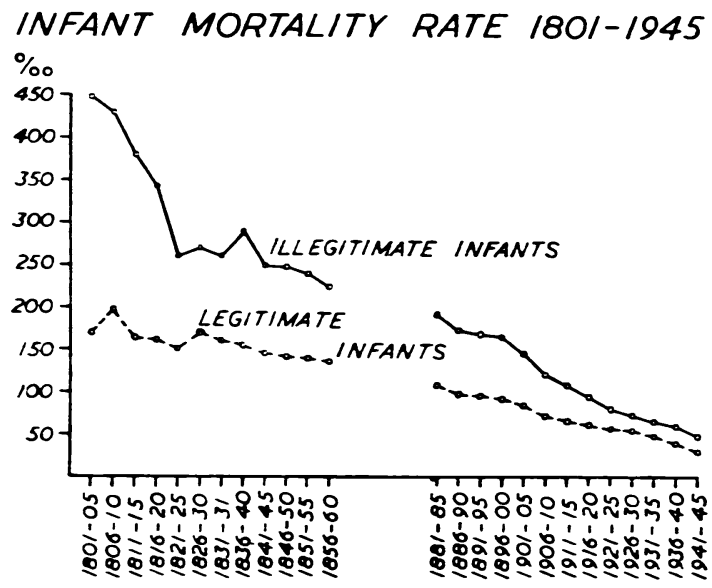

Fig. 16.

The inferior living conditions of the unmarried mother affect the child long before it is born. The pregnancy ends much more often in a missed abortion, or the infant frequently dies in utero or as a premature during the neonatal period. The newborn illegitimate child is apparently much the worse off. The incidence of stillbirths is also much higher when the mothers are not married. This is very important from the point of view of the population problem. In Sweden illegitimate children constitute a very large group. A decade ago the number of these children was $18 \%$ of all births and is now about $10 \%$. Unmarried mothers are usually poor women living in difficult circumstances. That there is a correlation between the infant mortality rate and the financial situation of the family is well known. It is obvious that a wealthy woman has a considerably greater chance to take care of herself during pregnancy than a woman who must work all day and has no time, or perhaps, because of fatigue, forgets to consider her own health. By raising the social and economic conditions of unmarried mothers to the level of married women it ought to be possible to decrease the higher mortality rate of the illegitimate children during the neonatal period. This has been done generously by the community which has provided financial support, ensured alimony from the father of the child, and satisfactory living conditions.

There is another factor which has a great influence on the poorer chance of life for the illegitimate child; they are mostly the first born and only child. It is well known that the first child runs greater risks than the next two. According to a British report, there were 54 neonatal deaths among every 1,000 first-born children, 31 among the second children, and 29 among the third. It is evident that the number of first deliveries is much higher in a population with a low birth rate than in one with a high birth rate. The lower the number of children born the greater is the number of first children and they have a higher mortality during the neonatal period. The higher the birth rate the more frequently will there be second and third children, and the lower should be the neonatal mortality. Therefore, an increase in the birth rate will influence the infant mortality rate, and, in turn, lead to a further increase in the number of children in the population.

\section{Social and Economic Factors Influencing the Birth Rate}

We now have returned to our starting point, the birth rate. Of importance both for an improved birth rate and for family life are satisfactory homes. Poor housing conditions counteract an increased birth rate. From a medical point of view the condition of the home is, of course, very important, especially when there are several children in the family. In narrow, dark, overcrowded, slum areas fewer children are healthy and develop satisfactorily. From this point of view the conditions in Sweden are not at all what they should be. Since the beginning of 1940 there has been an increasing scarcity of homes due mainly to the lack of labourers and building materials. This scarcity, most marked in the cities, makes the start of family life difficult for the unmarried and the bearing and upbringing of children difficult for the married. Living conditions 
in the cities discourage in another way an increase in the birth rate; more women tend to have work outside their homes than in the country districts. It is obvious that there is no reason why a family with children should have a lower income than a family or an unmarried woman without children. Nor is it right that a married woman with children should have to resign from a well paid job to be replaced by an unmarried woman or by a married woman with no children. On the contrary, if the family is in an unsatisfactory financial position, the wife must work in order to be able to help to support the family. Unfortunately work outside the home often directly leads to birth control and a childless marriage. The working married women in Sweden are more than twice as often childless as those who have no outside work, and those who have children have a number that is only half of that in families without working mothers. The number of working married women is not small; in Stockholm one-third of the married women work outside their homes. A woman who has a high income through her work does not like to leave this, to alter her habits or lower her standard of living, or to cut down on money for amusements and clothes. This is regarded as a great sacrifice and has to be done both when contemplating marriage and, if already married, when expecting the birth of a child.

A low population in any country is dangerous for that nation when neighbouring countries have an excess of population. The least unfortunate thing that may happen is immigration with all its biological and political consequences and its risks of destroying the original race. By the policy of admitting refugees which our government has justly followed since the first world war we have already got an important foreign element in our population (Fig. 17). This has not always been to our benefit.

\section{IMMIGRANTS}

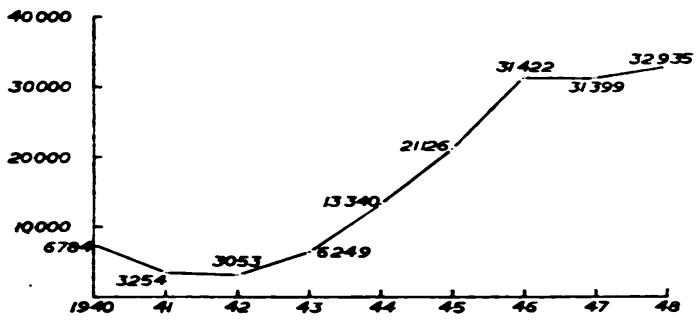

Fig. 17.

In addition, several groups of workers have been imported from Italy and Hungary in order to satisfy the demand for specially trained labour in factories and in the fields. This is only the beginning. In every profession we find more and more the same tendency towards a shortage of labour. From a medical point of view I only want to stress the shortage of nurses and hospital personnel which has resulted in the closing down of a great number of hospital wards. At present the Swedish government is busy arranging for the admission of 200 physicians from Austria in order to fill vacancies in the ranks of our own profession.

The worst thing that can happen as the result of the declining birth rate and decreasing population is that we may become an easy prey for imperialistic foreign powers to the destruction of our culture and the annihilation of the Nordic race. History tells us what the future of a people may be if the birth rate remains low and if the influx to the towns continues. Thus the much admired ancient Hellenic people succumbed. One of the great Greek historians, Polybius (c. 201-121 B.c.) said that the most fertile group of the Hellenic people, the farmers, had decreased in numbers by emigrating into the towns. The whole of Greece suffered from a low birth rate with the result that in time the fields lacked labourers, and even the cities began to have fewer and fewer inhabitants. The Hellenic people did not want to marry, and, if they did, they did not like to bring up many children, at most only one or two in order to allow these to grow up in prosperity and inherit an undivided fortume. The Hellenic people finally succumbed and Greece was invaded by a foreign race. Comparing only the problems of population of ancient Greece and those of presentday Sweden it is obvious how similar conditions are. We are afraid that what happened to the Hellenic people will happen to us.

This is the outline of the disquieting features of the population situation due to a declining birth rate in Sweden to-day. A low birth rate is not principally an economic problem; in the well-to-do classes of the population it is rather lower than in the lowest income group. The futility and fallacy of promoting an increased birth rate by different kinds of subsidies and the improvement of the general economic level has been sufficiently demonstrated. The only solution of the problem seems to be an increased marriage rate, an increased number of children in every family, a decreased emigration from rural districts, and improved housing facilities. Above all nations must be better informed of the consequences of a decrease in the population. Onty this, combined with propaganda for new ideals and a new outlook on life and a revaluation of those things that make life worth living, will permit future generations of our people to remain independent, free, and prosperous. 